\title{
Fault Diagnosis and Fault-Tolerant Control of Uncertain Robot Manipulators Using High-Order Sliding Mode
}

\author{
Mien Van, Pasquale Franciosa, and Dariusz Ceglarek \\ Manufacturing Systems and Digital Lifecycle Management Group, WMG, University of Warwick, Coventry, UK \\ Correspondence should be addressed to Mien Van; vanmien1@gmail.com
}

Received 16 March 2016; Revised 25 June 2016; Accepted 4 July 2016

Academic Editor: Kalyana C. Veluvolu

Copyright (C) 2016 Mien Van et al. This is an open access article distributed under the Creative Commons Attribution License, which permits unrestricted use, distribution, and reproduction in any medium, provided the original work is properly cited.

\begin{abstract}
A robust fault diagnosis and fault-tolerant control (FTC) system for uncertain robot manipulators without joint velocity measurement is presented. The actuator faults and robot manipulator component faults are considered. The proposed scheme is designed via an active fault-tolerant control strategy by combining a fault diagnosis scheme based on a super-twisting third-order sliding mode (STW-TOSM) observer with a robust super-twisting second-order sliding mode (STW-SOSM) controller. Compared to the existing FTC methods, the proposed FTC method can accommodate not only faults but also uncertainties, and it does not require a velocity measurement. In addition, because the proposed scheme is designed based on the high-order sliding mode (HOSM) observer/controller strategy, it exhibits fast convergence, high accuracy, and less chattering. Finally, computer simulation results for a PUMA560 robot are obtained to verify the effectiveness of the proposed strategy.
\end{abstract}

\section{Introduction}

Robotic systems which consist of robots, end effector, and fixtures holding parts are widely used in the processing and manufacturing industries to improve product quality [1-3]. Numerous manufacturing applications require robotic systems to be placed in production line that can lead to robot, end effector, and/or fixture failure. This can not only result in diminished product quality, but also cause harm to users and other objects in the workspace. In addition, it is difficult to repair failed robotic systems in dangerous environments. Hence, in some applications, it is important to design a control scheme to ensure that a robotic system can continue to reliably work in the presence of faults. A number of diagnostics approaches focus on diagnostics of end effector failures [4], fixture failure [5, 6], and/or robotics assembly system failures [7-11] based on in-line measurement of products [12]. However, there is an urgent need for diagnostics of robot operations under uncertainty and with minimum monitoring information needed.

Various fault diagnosis (FD) approaches for nonlinear and robotic systems have been studied over the last three decades. Model-based analytical redundancy schemes based on fault detection and isolation have previously been investigated $[13,14]$.

Using neural network (NN) learning, robust fault diagnosis methods have also been proposed [15-18]. However, the use of an $\mathrm{NN}$ observer does not guarantee finite time convergence. Hence, the performance of the NN-based FD system is somewhat weak. Due to its inherent robustness to system uncertainties and external disturbances $[19,20]$, the sliding mode technique has been used in the design of fault diagnostic observers [21-23]. However, a common drawback of the conventional sliding mode control (SMC) is the chattering phenomenon. To eliminate the chattering and obtain higher accuracy, high-order sliding mode (HOSM) techniques have been studied and applied for real applications. Unlike the classical SMC, which works on the first time derivative of the sliding variable, HOSM works with discontinuous control acting on the high-order time derivative. By moving the switching to the higher derivatives of the control, the control signal becomes continuous, so the chattering is eliminated. In another case, the main difficulty of other HOSMs, such as the suboptimal algorithm $[24,25]$, the twisting algorithm 
$[26,27]$, or the quasi-continuous $[28,29]$, is the necessity of using the first time derivative of the sliding variable. The super-twisting (STW) algorithm [30-37] does not require the time derivative of the sliding variable and is suitable for reconstruction of the velocities from the position information. For the states observer [28-30], the super-twisting HOSM observer has two inherent basic advantages [32-36]: (1) it provides the exact velocity estimation without filtration and (2) it allows the properties of equivalent control to be used to identify the unknown inputs. From the properties, super-twisting second-order sliding mode (STW-SOSM) observers have been used in the design of fault diagnostic observers for mechanical systems [37]. However, using the STW-SOSM observer, the unknown input is reconstructed from a discontinuous function, necessitating the application of a low-pass filter [37]. The application of the filter provides a time delay and error, which decrease the fault diagnosis performance. To address this problem, a super-twisting thirdorder sliding mode (STW-TOSM) observer [38-40] was applied to give both exact theoretical velocity estimations and an unknown input estimation without filtration for a spacecraft system.

In some robotic system applications, it is required that a fault should be automatically self-corrected after it is detected and isolated so as to enhance the system reliability and guarantee the control performance. This task is referred to as fault-tolerant control (FTC). In general, FTC systems can be divided into two categories [41, 42]: active and passive approaches. In passive FTC systems, one controller is used for both the normal case and the fault case without the need to detect the presence of a fault [43-45]. However, this approach requires partial knowledge of a possible system fault, so its use is limited in real applications. In an active system, FTC is designed based on fault information [15-18, 46-48]. FD is the first step to provide the fault information. The FTC scheme is then designed based on the obtained fault information in order to compensate for the effect of a fault in the system. For this reason, the system performance of the active FTC depends on the accuracy of the fault information that has been obtained. With the correct fault information, the performance of an active FTC system is more effective than that of a passive FTC system and hence is more desirable for practical applications. Conversely, incorrect fault information could lead to system instability and serious consequences.

Although many FTC schemes have been developed in the literature, to the best knowledge of the authors, there have been only minor FTC investigations for robotic systems, and most of these were designed based on modifications of the nominal computed torque controller (CTC) [27-29, 49]. The basic idea behind these approaches is to use a CTC along with estimated fault compensation, which is based on a feedback linearization technique. However, the use of CTC as a nominal controller has two major drawbacks in real robot applications [41, 44]. Firstly, it requires an exact model of the robot dynamics, which is usually impossible. Secondly, it is not robust to structured and unstructured uncertainties, which may result in poor performance. Therefore, these approaches do not compensate for the modeling uncertainty when designing the nominal controller for normal operation, although the uncertainty can be compensated when a fault occurs. Consequently, the tracking performance is decreased. In addition, these FTC schemes are designed based on the assumption that the velocity measurement is available. Unfortunately, the velocity measurement is obtained using tachometers, which are often contaminated by noise and increase the number of sensors that may reduce the control performance. Therefore, it is important to investigate an FTC scheme using correct fault information and with only a joint position measurement.

In this paper, a new FD and FTC scheme for uncertain robot manipulators with only a position measurement is presented based on super-twisting HOSM controller and observer to compensate both the uncertainties and faults and obtain fast convergence, high accuracy, and less chattering. For fault diagnosis, a STW-TOSM observer is designed. The obtained equivalent output injection (EOI) of the STWTOSM observer is used to identify unknown faults, which can be used as residuals for the problem of fault detection and isolation. In the second part, a SMC is employed to design the FTC scheme. First, a passive FTC scheme that does not require the FD information is designed based on the estimated states and conventional SMC, and the disadvantage of this type of scheme is discussed. Then, in order to obtain better performance, an active FTC based on the estimated states, estimated faults, and a conventional SMC is designed. Compared to the passive FTC, the proposed active FTC has smaller control effort results, and the chattering phenomenon is much reduced. Furthermore, to alleviate the chattering and obtain higher accuracy, an STW-SOSM controller is employed instead of the conventional SMC. The stability and convergence of the FTC system are demonstrated by the Lyapunov theory.

The remainder of this paper is organized as follows. In Section 2, the robot dynamics and faults are investigated, and problems are described. In Section 3, fault diagnosis schemes are designed based on the STW-TOSM observer. The proposed passive FTC and active FTC based on the STWSOSM controller and the STW-TOSM observer are discussed in Section 4. The computer simulation results for a PUMA560 robot are given in Section 5 so as to verify the effectiveness of the proposed algorithm. Finally, the conclusions are presented in Section 6.

\section{Problem Statements}

Consider the robot dynamics described by

$$
\begin{aligned}
\ddot{q}= & M^{-1}(q)\left(\tau-V_{m}(q, \dot{q}) \dot{q}-F(\dot{q})-G(q)-\tau_{d}\right) \\
& +\beta\left(t-T_{f}\right) \phi(q, \dot{q}, \tau),
\end{aligned}
$$

where $q, \dot{q}, \ddot{q} \in \mathfrak{R}^{n}$ are the vectors of joint positions, velocities, and accelerations, respectively, $\tau \in \mathfrak{R}^{n}$ is the torque produced by actuators, $M(q) \in \mathfrak{R}^{n \times n}$ is the inertia matrix, $V_{m}(q, \dot{q}) \in$ $\mathfrak{R}^{n}$ are the Coriolis and centripetal torques, $F(\dot{q}) \in \mathfrak{R}^{n}$ is the friction matrix, $\tau_{d} \in \Re^{n}$ is a load disturbance matrix, $G(q) \in \mathfrak{R}^{n}$ is the gravity torque term, $\phi(q, \dot{q}, \tau) \in \mathfrak{R}^{n}$ is a vector composed of actuator faults and component faults, 
$\beta\left(t-T_{f}\right) \in \mathfrak{R}^{n}$ represents the time profile of the faults, and $T_{f}$ is the time of occurrence of the faults; that is,

$$
\beta_{i}\left(t-T_{f}\right)= \begin{cases}0 & \text { if } t<T_{f} \\ 1-e^{-\varphi_{i}}\left(t-T_{f}\right) & \text { if } t \geq T_{f}\end{cases}
$$

where $\varphi_{i}>0$ represents the unknown fault evolution rate. A small value of $\varphi_{i}$ characterizes a slowly developing fault, also called an incipient fault. For a large value of $\varphi_{i}$, the profile of $\beta_{i}$ approaches a step function that models abrupt faults. When $\varphi_{i} \rightarrow \infty, \beta_{i}$ becomes a step function so that the incipient fault becomes an abrupt fault.

To simplify the subsequent design and analysis, (1) can be rewritten as

$$
\begin{aligned}
\ddot{q}= & M^{-1}(q)(\tau-H(q, \dot{q}))+\Delta(q, \dot{q}, t) \\
& +\beta\left(t-T_{f}\right) \phi(q, \dot{q}, \tau),
\end{aligned}
$$

where $H(q, \dot{q})=V(q, \dot{q})+G(q)$ and $\Delta(q, \dot{q}, t)=$ $M^{-1}(q)\left(-F(\dot{q})-\tau_{d}\right)$ represents the modeling uncertainty in the dynamic model of robot manipulators.

In this paper, we investigate two ideas for an uncertain robot manipulator with the dynamic model described in (3): first, we develop a STW-TOSM observer to estimate the system states and the fault information signals simultaneously. The fault information is then used for fault detection and isolation as well as fault accommodation. Second, we develop an active FTC scheme by using the estimated states, estimated faults, and an STW-SOSM controller to accommodate the effects of uncertainties and faults so as to stabilize and increase the tracking performance of the robot manipulator in both fault-free and fault operation modes. The basic idea of the design can be depicted in Figure 1. Here, the following assumptions are made.

Assumption 1. The modeling uncertainty is bounded such that

$$
\left\|M^{-1}(q)\left(F(\dot{q})+\tau_{d}\right)\right\|=\Delta(q, \dot{q}, t) \leq \bar{\Delta},
$$

where $\bar{\Delta}$ is a known constant.

Assumption 2. The unknown fault function is bounded as

$$
\|\phi(q, \dot{q}, t)\|<\bar{\phi}
$$

where $\bar{\phi}$ is a known constant.

\section{States Observer and Fault Diagnosis Observer Scheme Based on a Super-Twisting Third-Order Sliding Mode Observer}

In this section, the observer scheme that is used for both state observer and fault diagnosis based on STW-TOSM observer is described.
3.1. Fault Diagnosis Scheme Based on a Super-Twisting ThirdOrder Sliding Mode (STW-TOSM) Observer. With $x_{1}=q \epsilon$ $\mathfrak{R}^{n}$ and $x_{2}=\dot{q} \in \mathfrak{R}^{n}$, the robot dynamics expressed in (3) can be written in state-space form as

$$
\begin{aligned}
\dot{x}_{1}= & x_{2}, \\
\dot{x}_{2}= & f\left(x_{1}, x_{2}, \tau\right)+\Delta\left(x_{1}, x_{2}, t\right) \\
& +\beta\left(t-T_{f}\right) \phi\left(x_{1}, x_{2}, \tau\right), \\
y= & x_{1},
\end{aligned}
$$

where $f\left(x_{1}, x_{2}, \tau\right)=M^{-1}(q)\left[\tau-V_{m}(q, \dot{q}) \dot{q}-G(q)\right]$.

We consider an STW-TOSM observer with the following form [38-40]:

$$
\begin{aligned}
\dot{\hat{x}}_{1}= & \widehat{x}_{2}+\alpha_{2}\left\|x_{1}-\hat{x}_{1}\right\|^{2 / 3} \operatorname{sign}\left(x_{1}-\widehat{x}_{1}\right), \\
\dot{\hat{x}}_{2}= & f\left(x_{1}, \hat{x}_{2}, \tau\right)+\alpha_{1}\left\|\dot{\hat{x}}_{1}-\hat{x}_{2}\right\|^{1 / 2} \operatorname{sign}\left(\dot{\hat{x}}_{1}-\widehat{x}_{2}\right) \\
& +\widehat{z}_{\text {eq }}, \\
\dot{\vec{z}}_{\text {eq }}= & \alpha_{0} \operatorname{sign}\left(\dot{\hat{x}}_{1}-\hat{x}_{2}\right),
\end{aligned}
$$

where $\alpha_{i}$ is the sliding mode gain to be designed.

Substituting (6) into (7), the state estimation error is defined as

$$
\begin{aligned}
\dot{\tilde{x}}_{1}= & \tilde{x}_{2}-\alpha_{2}\left\|x_{1}-\hat{x}_{1}\right\|^{2 / 3} \operatorname{sign}\left(x_{1}-\widehat{x}_{1}\right), \\
\dot{\tilde{x}}_{2}= & d\left(x_{1}, \widehat{x}_{2}, \tilde{x}_{2}\right)+\Delta\left(x_{1}, x_{2}, t\right)+\phi\left(x_{1}, x_{2}, \tau\right) \\
& -\alpha_{1}\left\|\dot{\hat{x}}_{1}-\hat{x}_{2}\right\|^{1 / 2} \operatorname{sign}\left(\dot{\hat{x}}_{1}-\widehat{x}_{2}\right)-\widehat{z}_{\text {eq }}, \\
\dot{\vec{z}}_{\mathrm{eq}}= & \alpha_{0} \operatorname{sign}\left(\dot{\hat{x}}_{1}-\hat{x}_{2}\right),
\end{aligned}
$$

where $\tilde{x}_{i}=x_{i}-\hat{x}_{i}(i=1,2)$ and $d\left(x_{1}, \hat{x}_{2}, \tilde{x}_{2}\right)=f\left(x_{1}, x_{2}, \tau\right)-$ $f\left(x_{1}, \widehat{x}_{2}, \tau\right)$. If we define $F\left(x_{1}, x_{2}, \widehat{x}_{2}, \tau\right)=d\left(x_{1}, \widehat{x}_{2}, \widetilde{x}_{2}\right)+$ $\Delta\left(x_{1}, x_{2}, t\right)+\phi\left(x_{1}, x_{2}, \tau\right)$, based on Assumptions 1 and 2 , there exists a constant $f^{+}$such that

$$
F\left(x_{1}, x_{2}, \hat{x}_{2}, \tau\right)<f^{+} .
$$

Based on the analysis in [38-40], the sliding gains can be selected as $\alpha_{0}=1.1 f^{+}, \alpha_{1}=1.5\left(f^{+}\right)^{1 / 2}$, and $\alpha_{2}=1.9\left(f^{+}\right)^{1 / 3}$ to guarantee the stability and convergence.

After convergence of the differentiator, the estimation states $\left(\hat{x}_{1}, \hat{x}_{2}\right)$ converge to the true state $\left(x_{1}, x_{2}\right)$, and the following equalities are satisfied:

$$
\begin{aligned}
& \Delta\left(x_{1}, x_{2}, t\right)+\phi\left(x_{1}, x_{2}, \tau\right) \\
& \quad-\alpha_{1}\left\|\dot{\hat{x}}_{1}-\widehat{x}_{2}\right\|^{1 / 2} \operatorname{sign}\left(\dot{\hat{x}}_{1}-\widehat{x}_{2}\right)-\widehat{z}_{\text {eq }}=0 .
\end{aligned}
$$

When the differentiator converges to zero, the third term of (10) is equal to zero. The uncertainties and faults can then be reconstructed as

$$
\widehat{z}_{\text {eq }}=\Delta\left(x_{1}, x_{2}, t\right)+\phi\left(x_{1}, x_{2}, \tau\right) .
$$

In (7) and (11), $\widehat{z}_{\text {eq }}$ is a continuous term and thus a low-pass filter is not needed to obtain the equivalent output injection. Consequently, they are an exact theoretical estimation of the unknown inputs (uncertainties and faults) without filtration. This is very useful in designing the active FTC, which requires accurate fault estimation. 
3.2. Fault Detection and Isolation Decision. The proposed STW-TOSM observer is able to detect system faults in the presence of uncertainties. The fault diagnosis system must be robust against system uncertainties but must also be sensitive to any fault. In this paper, the obtained EOI of the STWTOSM in (7) is used as a residual to detect and isolate faults.

According to (2), $\phi(q, \dot{q}, \tau)=0$ when $t<T_{f}$, the system in normal operation. Then, from (11), $\widehat{z}_{\text {eq }}=\Delta(q, \dot{q}, t)$, and from Assumption 2 we have

$$
\widehat{z}_{\mathrm{eq}}=\Delta\left(x_{1}, x_{2}, t\right) \leq \bar{\Delta}=z_{\mathrm{th}}
$$

The threshold is chosen such that the residual can clearly distinguish between normal operation and fault operation. Because the residual $\widehat{z}_{\text {eq }}$ is always smaller than $z_{\text {th }}$ in normal operation, $z_{\text {th }}$ is chosen as the threshold [47]. When a fault occurs, the residual $\widehat{z}_{\mathrm{eq}}=\Delta\left(x_{1}, x_{2}, t\right)+\phi(q, \dot{q}, \tau)>z_{\mathrm{th}}$, and the fault is declared. Thus, fault is detected and isolated whenever the residual $\left(\widehat{z}_{\text {eq }}\right)$ overshoots its corresponding threshold $\left(z_{\text {th }}\right)$.

\section{Sliding Mode Fault-Tolerant Control}

In this section, two robust FTC schemes based on SMC are designed and analyzed. The goal of both active and passive FTC schemes is to achieve acceptable performance and stability for a healthy system as well as for a faulty system. First, a passive FTC scheme that does not depend on the fault diagnosis information is designed using the estimated states and a conventional SMC, and its disadvantage is discussed. Then, a new active FTC scheme is designed based on the estimated states, estimated faults, and conventional SMC. Finally, to reduce the chattering and obtain higher accuracy, an STWSOSM controller is employed to replace the conventional SMC.

4.1. Passive FTC Based on the Estimated States and a Conventional Sliding Mode Controller. The objective of the passive FTC system design is to use a single fixed controller to accommodate all expected system faults.

From (3), when a fault occurs, the robot dynamics can be rewritten as

$$
\begin{aligned}
\dot{x}_{1}= & x_{2}, \\
\dot{x}_{2}= & M^{-1}\left(x_{1}\right) u+g\left(x_{1}, x_{2}\right)+\Delta\left(x_{1}, x_{2}, t\right) \\
& +\phi\left(x_{1}, x_{2}, u\right),
\end{aligned}
$$

where $u=\tau$ is the control input and $g\left(x_{1}, x_{2}\right)=$ $M^{-1}\left(x_{1}\right)\left(-V_{m}(q, \dot{q}) \dot{q}-G(q)\right)$.

Based on the sliding mode design procedure [19], the control system design includes two main steps. The first step involves constructing the desired sliding surface, which is chosen such that when it converges to zero, the desired control is achieved. The next step is to select a control law that forces the system state to reach the sliding surface in a finite amount of time. For the first step, we let

$$
e=x_{1}-x_{d}
$$

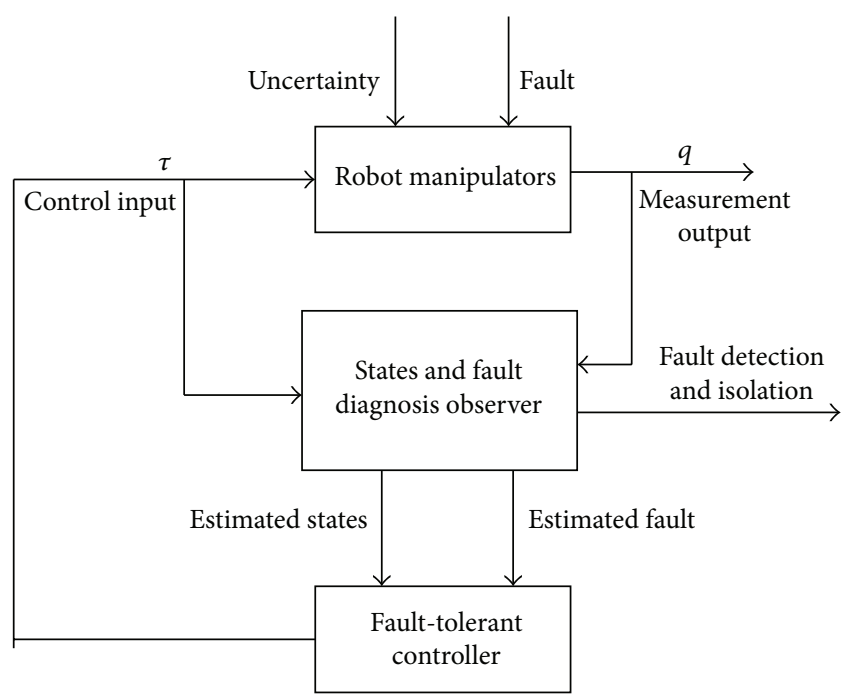

FIGURE 1: Block diagram for fault diagnosis and fault-tolerant control.

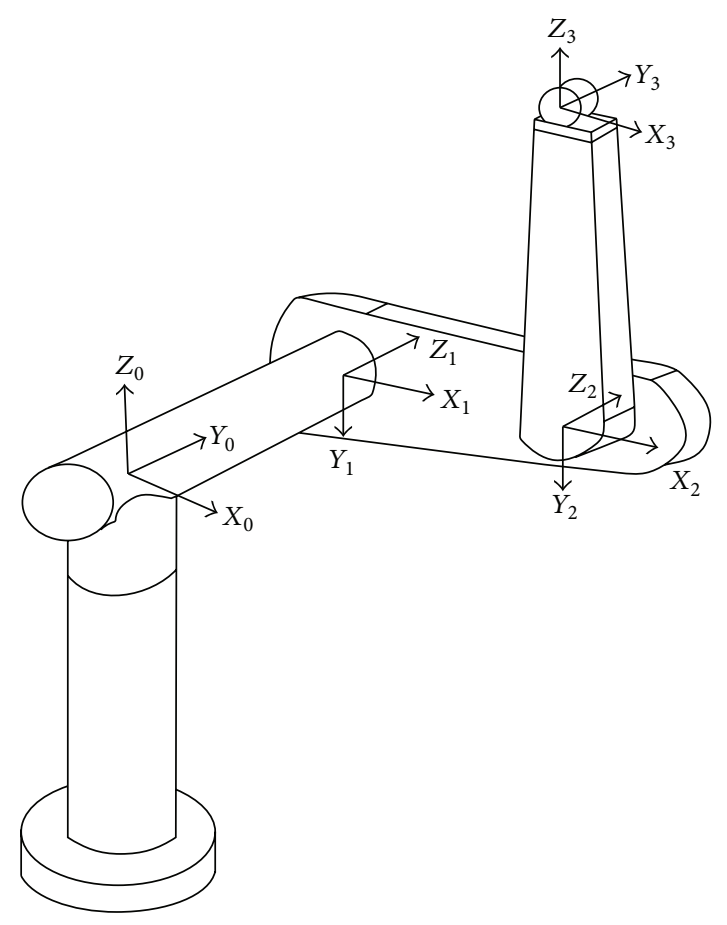

FIGURE 2: 3-DOF PUMA560 robot.

and the sliding surface is selected as

$$
s=\dot{e}+\lambda e,
$$

where $\lambda$ is a strictly positive constant. It is obvious that if the system state remains on the sliding surface, the desired control task $e \rightarrow 0$ can be achieved.

For the second step, to ensure that the trajectories of the system approach the sliding surface, in the presence of 


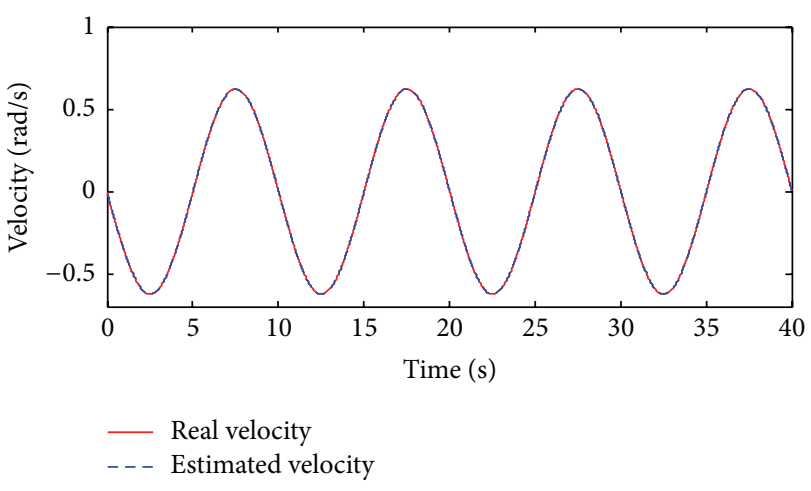

(a) Joint 1

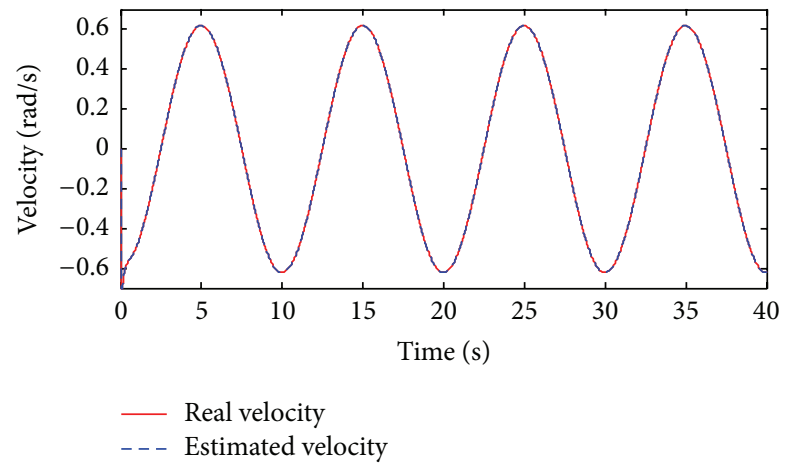

(b) Joint 2

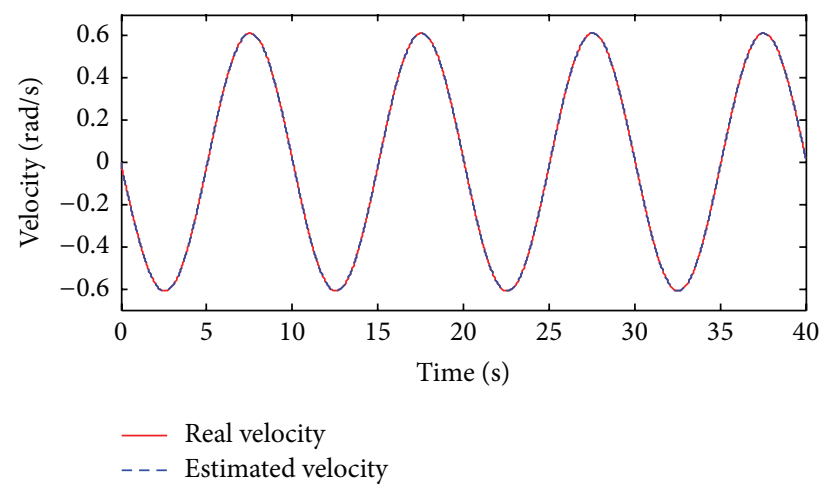

(c) Joint 3

FIGURE 3: Real and estimated velocities.

uncertainties, the derivative of the sliding surface $\dot{s}=0$ should be satisfied such that

$$
\begin{aligned}
\dot{s}= & \ddot{e}+\lambda \dot{e} \\
= & M^{-1}\left(x_{1}\right) u+g\left(x_{1}, x_{2}\right)+\Delta\left(x_{1}, x_{2}, t\right) \\
& +\phi\left(x_{1}, x_{2}, u\right)-\ddot{x}_{d}+\lambda\left(x_{2}-\dot{x}_{d}\right)=0 .
\end{aligned}
$$

According to the sliding mode design procedure, the SMC law for an uncertain robot system will be designed as

$$
u=u_{\mathrm{eq}}+u_{u}+u_{f}
$$

where

$$
u_{\mathrm{eq}}=M\left(x_{1}\right)\left(\ddot{x}_{d}-\lambda\left(\hat{x}_{2}-\dot{x}_{d}\right)-g\left(x_{1}, \hat{x}_{2}\right)\right),
$$

where $\hat{x}_{2}$ is the estimation of $x_{2}$, which can be obtained from the STW-TOSM observer-based states observer, and $u_{u}$ is the term that compensates for the effect of the uncertainties. It is designed such that

$$
u_{u}=-M\left(x_{1}\right) \rho_{u} \operatorname{sign}(s),
$$

where $\rho_{u}$ is a constant chosen based on the upper bound of the modeling uncertainties; that is, $\rho_{u} \geq \bar{\Delta}$ [48].

And $u_{f}$ is the term that compensates for the effect of the fault, and it is designed such that [48]

$$
u_{f}=-M\left(x_{1}\right) \rho_{f} \operatorname{sign}(s),
$$

where $\rho_{f}$ is a constant chosen based on the upper bound of the possible faults occurring in the system; that is, $\rho_{f} \geq \bar{\phi}$.
Remark 3. For a simple analysis, the passive FTC control scheme in (17) can be rewritten as

$$
u=u_{\mathrm{eq}}+u_{u f}
$$

where

$$
u_{u f}=u_{u}+u_{f}=-M\left(x_{1}\right) \rho_{u f} \operatorname{sign}(s) .
$$

The sliding gain is chosen such that $\rho_{u f}=\rho_{u}+\rho_{f} \geq \bar{\Delta}+\bar{\phi}$.

4.2. Active FTC Based on Estimated State, Estimated Fault, and an STW-SOSM Controller. In this section, the proposed active FTC is described and compared with that of the passive conventional sliding mode FTC. The design procedure includes three steps (Figure 1). First, an STW-TOSM observer-based fault diagnosis scheme is developed to obtain the fault information. Then, the obtained fault information is used to compensate for the fault effect in the system by using a feedback control technique. Finally, the STWSOSM controller is employed to compensate for the fault compensation error, to guarantee that the system is stable and to ensure finite time convergence.

4.2.1. Active FTC Based on Conventional Sliding Mode Control and Fault Estimation. According to the design procedure illustrated in Figure 1, the proposed active FTC is designed as

$$
u=u_{\mathrm{eq}}+u_{c}+u_{s}
$$




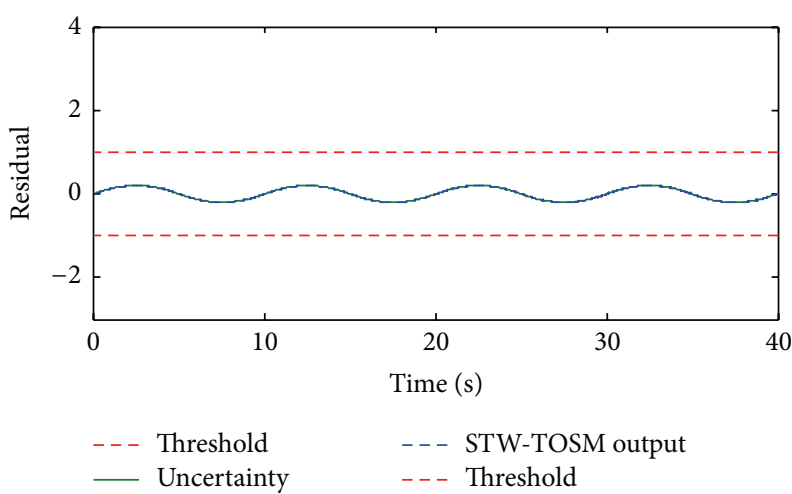

(a) Residual 1

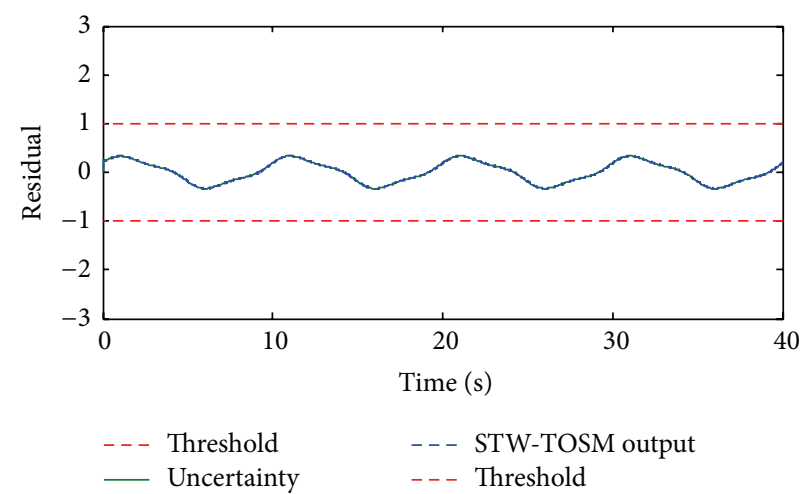

(b) Residual 2

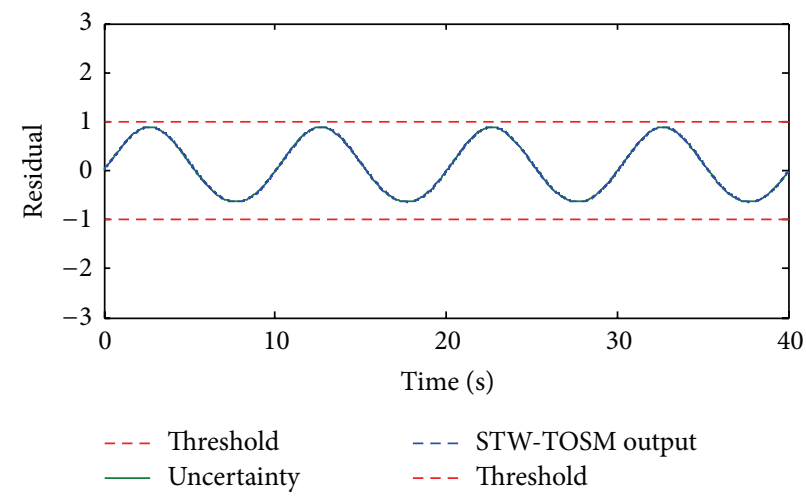

(c) Residual 3

FIGURE 4: Residuals of a healthy system (solid lines) and the selection threshold (dashed lines).

where $u_{\mathrm{eq}}$ is designed as in (18) and is used to control the nominal system. $u_{c}$ is the compensated uncertainty and fault based on the obtained EOI of the STW-TOSM observer and $u_{s}$ is used to compensate for the STW-TOSM compensation error. These parameters are designed such that

$$
u_{c}=-M\left(x_{1}\right) \widehat{z}_{\mathrm{eq}}
$$

and the parameter $u_{s}$ is designed such that

$$
u_{s}=-M\left(x_{1}\right) v \operatorname{sign}(s),
$$

where $v$ is the sliding mode gain.

The derivative of the sliding surface is now obtained under the control input expressed in (23) as

$$
\begin{aligned}
\dot{s}= & \ddot{e}+\lambda \dot{e} \\
= & M^{-1}\left(x_{1}\right)\left(u_{\mathrm{eq}}+u_{c}+u_{s}\right)+g\left(x_{1}, x_{2}\right) \\
& +\Delta\left(x_{1}, x_{2}, t\right)+\phi\left(x_{1}, x_{2}, u\right)-\ddot{x}_{d}+\lambda\left(x_{2}-\dot{x}_{d}\right) \\
= & M^{-1}\left(x_{1}\right)\left(u_{s}\right)-\widehat{z}_{\mathrm{eq}}+\Delta\left(x_{1}, x_{2}, t\right)+\phi\left(x_{1}, x_{2}, u\right) \\
= & M^{-1}\left(x_{1}\right)\left(u_{s}\right)-\left(\widehat{\Delta}\left(x_{1}, x_{2}, t\right)+\widehat{\phi}\left(x_{1}, x_{2}, u\right)\right) \\
& +\Delta\left(x_{1}, x_{2}, t\right)+\phi\left(x_{1}, x_{2}, u\right) \\
= & -v \operatorname{sign}(s)+\varepsilon_{1}+\varepsilon_{2},
\end{aligned}
$$

where $\widehat{\Delta}\left(x_{1}, x_{2}, t\right)$ and $\widehat{\phi}\left(x_{1}, x_{2}, u\right)$ are the uncertainty and fault estimations provided by the EOI of the STW-TOSM observer, respectively, $\varepsilon_{1}=\Delta\left(x_{1}, x_{2}, t\right)-\widehat{\Delta}\left(x_{1}, x_{2}, t\right)$ is the uncertainty estimation error, and $\varepsilon_{2}=\phi\left(x_{1}, x_{2}, \tau\right)-\widehat{\phi}\left(x_{1}\right.$, $\left.x_{2}, \tau\right)$ is the fault estimation error. Due to the ability of the STW-TOSM observer to be robust toward uncertainties and faults, the estimation errors are bounded such that $\varepsilon_{1} \leq \bar{\varepsilon}_{1}$ and $\varepsilon_{2} \leq \bar{\varepsilon}_{2}$.

To ensure that the sliding surface $s$ converges to zero, the sliding mode gain in (25) is chosen such that $v \geq\left\|\bar{\varepsilon}_{1}+\bar{\varepsilon}_{2}\right\|$ $[19,48]$. Because $\bar{\varepsilon}_{1} \ll \bar{\Delta}$ and $\bar{\varepsilon}_{2} \ll \bar{\phi}$, the sliding mode gains $v$ in the active FTC scheme (25) could be selected to be much smaller than those $\rho_{u f}$ in the passive FTC scheme (22) in Section 4.1. Consequently, the chattering generated by (25) is significantly decreased compared with that of (22). This means that when the fault information of the fault diagnosis observer is correct, the performance of the active FTC is better than that of the passive FTC.

\subsubsection{Active FTC Based on a Super-Twisting Second-Order} Sliding Mode Controller and Fault Estimation. Although the active FTC scheme in (23) can reduce the chattering due to the reduced sliding gain in the switching term, the use of the discontinuous sign function of the conventional SMC still generates chattering. To remove the chattering and to obtain higher accuracy, an STW-SOSM controller is designed to replace the conventional SMC. Because the super-twisting 


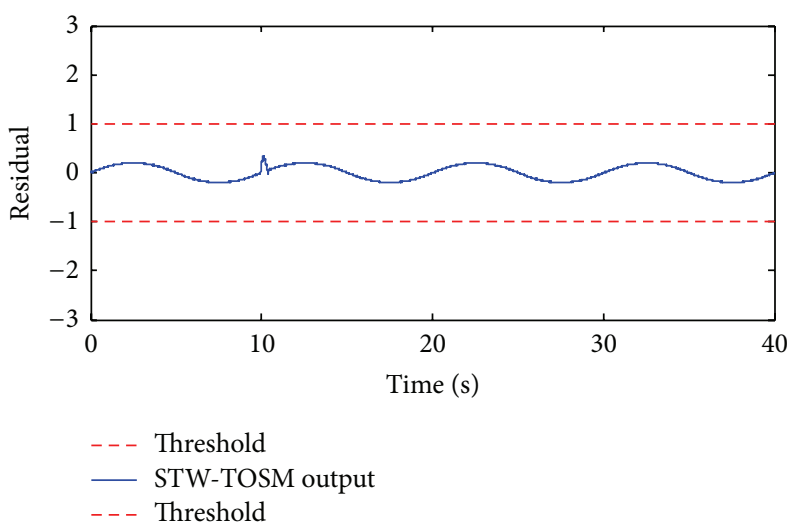

(a) Residual 1

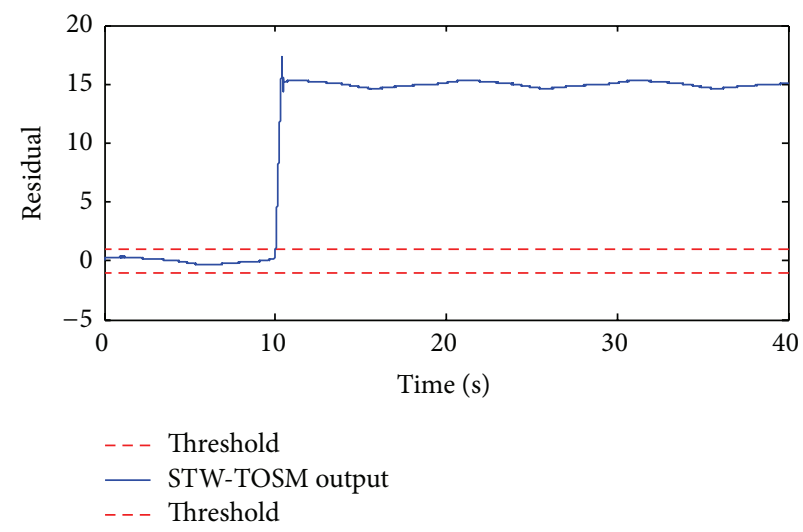

(b) Residual 2

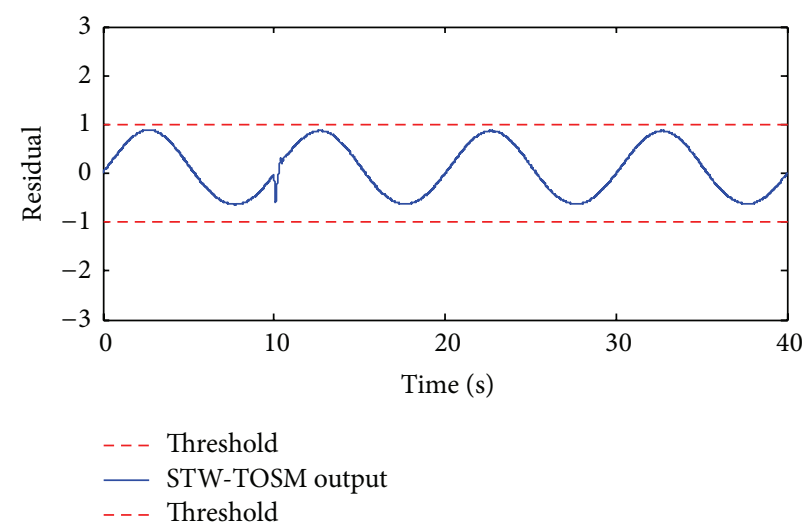

(c) Residual 3

FIGURE 5: Residuals of a faulty system (solid lines) under the effect of fault $\delta \tau_{1}$ and the selection thresholds (dashed lines).

algorithm contains a discontinuous function under the integral, the chattering is not eliminated but is greatly attenuated.

Starting from (26) with $u_{\mathrm{eq}}$ and $u_{c}$ given in (18) and (24), respectively, the derivative of the sliding surface $\dot{s}$ can be rewritten as

$$
\dot{s}=M^{-1}\left(x_{1}\right) u_{s}+\varphi\left(t, x_{1}, x_{2}\right),
$$

where $u_{s}$, the control input, is now designated based on the STW-SOSM controller and $\varphi\left(t, x_{1}, x_{2}\right)=\varepsilon_{1}+\varepsilon_{2} \leq \bar{\varepsilon}_{1}+\bar{\varepsilon}_{2}=\bar{\varepsilon}$ is assumed to be an unknown perturbation bounded term. At this point, one can propose the stability of the STW-SOSM controller as follows [30, 50]:

$$
\begin{aligned}
u_{s} & =-M\left(x_{1}\right) u_{\text {STW-SOSM }}, \\
u_{\text {STW-SOSM }} & =k_{1}\|s\|^{1 / 2} \operatorname{sign}(s)-z_{2}, \\
\dot{z}_{2} & =-k_{2} \operatorname{sign}(s) .
\end{aligned}
$$

From (27) and (28), the closed loop error dynamics are given by

$$
\begin{aligned}
\dot{s} & =-k_{1}\|s\|^{1 / 2} \operatorname{sign}(s)+z_{2}+\varphi\left(t, x_{1}, x_{2}\right), \\
\dot{z}_{2} & =-k_{2} \operatorname{sign}(s) .
\end{aligned}
$$

The sliding gains are selected as follows to guarantee the stability and convergence $[32,50]$ :

$$
\begin{aligned}
& k_{1}>2 \bar{\varepsilon}, \\
& k_{2}>k_{1} \frac{5 k_{1}+4 \bar{\varepsilon}}{\left(2 k_{1}-4 \bar{\varepsilon}\right)} \bar{\varepsilon},
\end{aligned}
$$

and then the sliding surface $s$ is stable and converges to zero in finite time.

Remark 4. Because $\bar{\varepsilon}$ is the bound value of the STW-TOSM estimation error, we can determine this value based on experiments by observing the STW-TOSM estimation error. However, due to the estimation capability of the sliding mode observer, the observer error is usually very small. Thus, the sliding gains can be selected as a small value to guarantee the condition (30).

Remark 5 (see [47]). No matter what the control input is, the STW-TOSM observer can obtain a finite time convergence [38-40]. This means that the controller and observer (7) can be designed separately. Therefore, if the stability of the observer and controller can be guaranteed separately, the closed loop observer-controller can be successfully applied without any stability problem. 


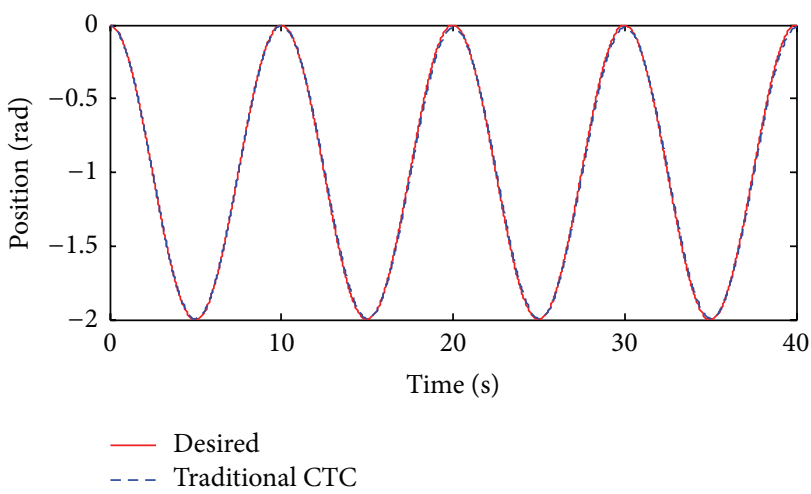

(a) Joint 1

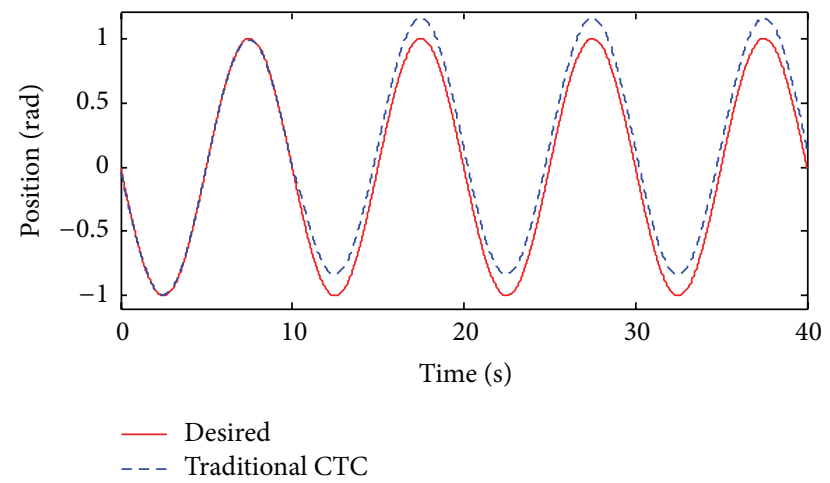

(b) Joint 2

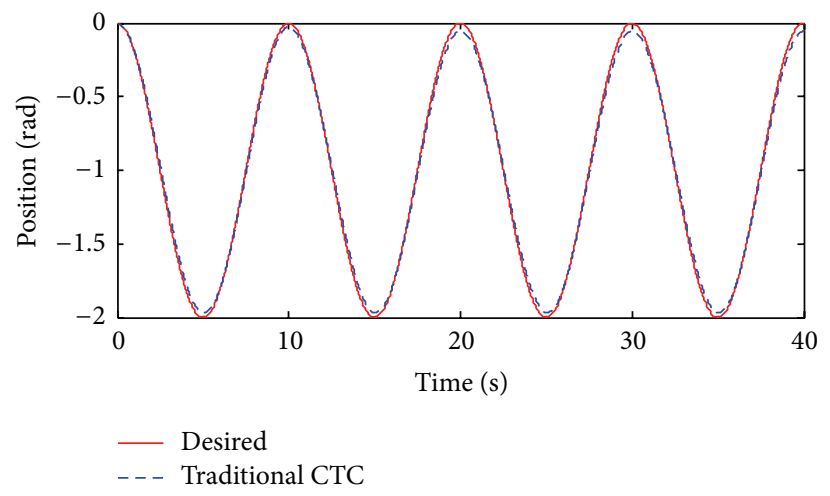

(c) Joint 3

Figure 6: The desired trajectories (dashed lines) and joint angles of the robot manipulator when an actuator fault $\delta \tau_{1}$ occurs under the traditional CTC controller.

\section{Simulation Results}

In order to verify the effectiveness of the proposed FD and FTC algorithm, its overall procedure is simulated for a PUMA560 robot in which the first three joints are used. The PUMA560 robot is a well-known industrial robot that has been widely used in industrial applications and robotic research. The explicit dynamic model and parameter values necessary to control the robot are given in [51].

The three-degree of freedom (3-DOF) PUMA560 robot is considered with the last three joints locked. A kinematic description of the robot is given in Figure 2. The uncertainties used in this simulation are as follows:

$$
\begin{aligned}
F(\dot{q}) & =\left[\begin{array}{c}
0.1 \dot{q}_{1}+0.02 \sin \left(3 q_{1}\right) \\
0.2 \dot{q}_{2}+0.2 \sin \left(2 q_{2}\right) \\
1.1 \dot{q}_{3}+0.15 \sin \left(q_{3}\right)
\end{array}\right], \\
\tau_{d} & =\left[\begin{array}{c}
0.2 \sin \left(\dot{q}_{1}\right) \\
0.1 \sin \left(\dot{q}_{2}\right) \\
0.15 \sin \left(\dot{q}_{3}\right)
\end{array}\right] .
\end{aligned}
$$

MATLAB/Simulink is used to perform all of the simulations; the sampling time was set as $10^{-4} \mathrm{~s}$. An actuator fault is considered in the simulations because it represents one of the most serious failures and usually occurs in robotic systems.
In a robotic system, damage to the actuators can be caused by damage to an internal actuator, the power supply systems, or wirings. This class of failure can be described by the difference between the nominal torque $\tau_{0}$ and the actual torque $\tau$ acting at the robot joint; it can be expressed as [52]

$$
\tau(t)=\tau_{0}(t)+\delta \tau(t)
$$

The actuator fault $\delta \tau(t)$ can be represented by the fault $\phi(q, \dot{q}, \tau)$ in $(1)$ as $\phi(q, \dot{q}, \tau)=M^{-1}(q) \delta \tau(t)$. Consequently, the actuator fault estimation can be reconstructed from the EOI of the STW-TOSM observer as $\delta \widehat{\tau}(t)=M(q) \widehat{z}_{\text {eq }}$, where $\delta \widehat{\tau}(t)$ is the estimation of the real actuator fault $\delta \tau(t)$.

The simulations are divided into two sets to verify the capability of the proposed FD and FTC scheme, respectively. At first, we will illustrate the capability of the STW-TOSM observer in state estimation and fault detection and isolation. The parameters of the STW-TOSM observer are chosen as $\alpha_{0}=1.1 L, \alpha_{1}=1.5 L^{1 / 2}$, and $\alpha_{2}=1.9 L^{1 / 3}$, where the uncertainties and faults are assumed to be bounded by $L=$ $\bar{C}=15$. The states estimation and EOI of the STW-TOSM observer in normal operation are shown in Figures 3 and 4, respectively. As evident in Figure 3, the STW-TOSM observer provides exact velocity estimation. Additionally, the EOI of the STW-TOSM observer provides the exact uncertainty estimation without filtration, as shown in Figure 4. For this reason, it is used as the residual to detect and isolate the 


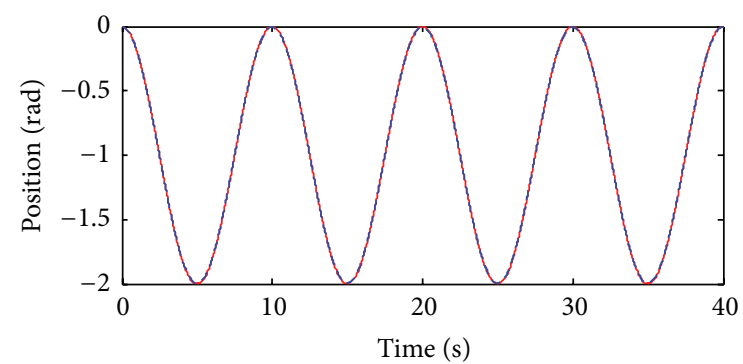

— Desired

- - - Active CTC-FTC

(a) Joint 1

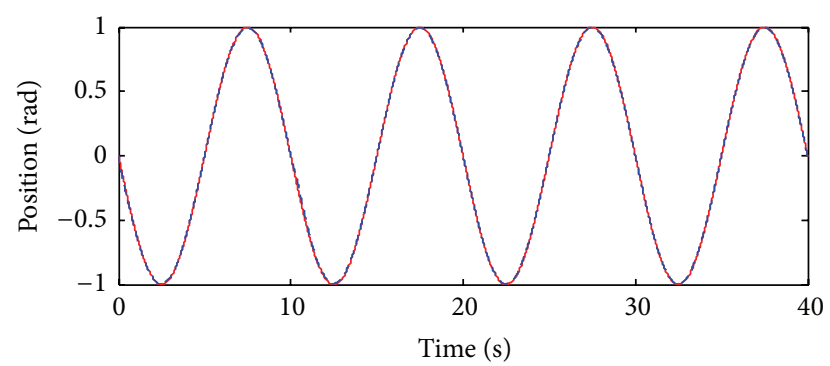

— Desired

- - - Active CTC-FTC

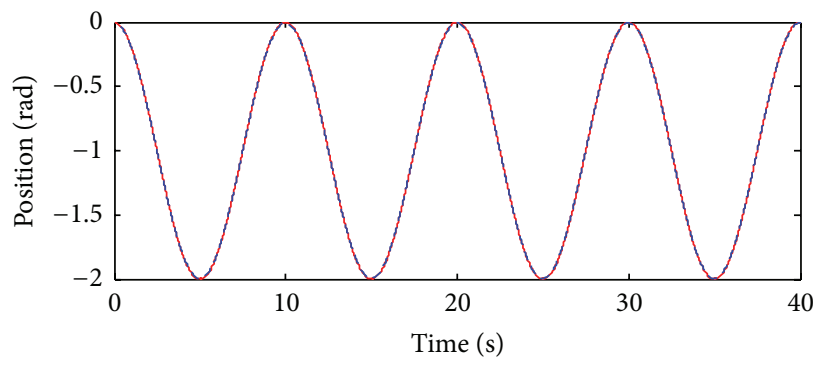

— Desired

- - - Active CTC-FTC

(c) Joint 3

FIgURE 7: The desired trajectories (dashed lines) and joint angles of the robot manipulator when an actuator fault $\delta \tau_{1}$ occurs under the Active CTC-FTC.

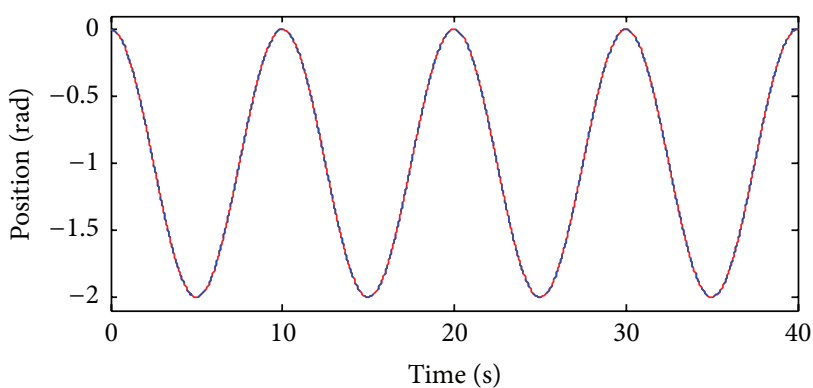

- Desired

- - - Active STW-SOSM-FTC

(a) Joint 1

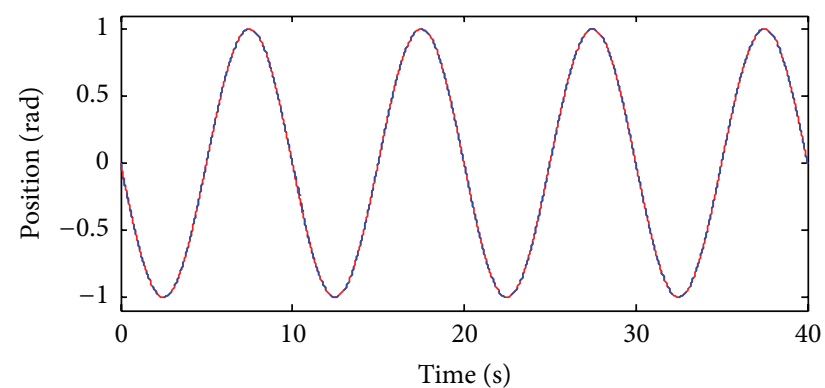

— Desired

- - - Active STW-SOSM-FTC

(b) Joint 2

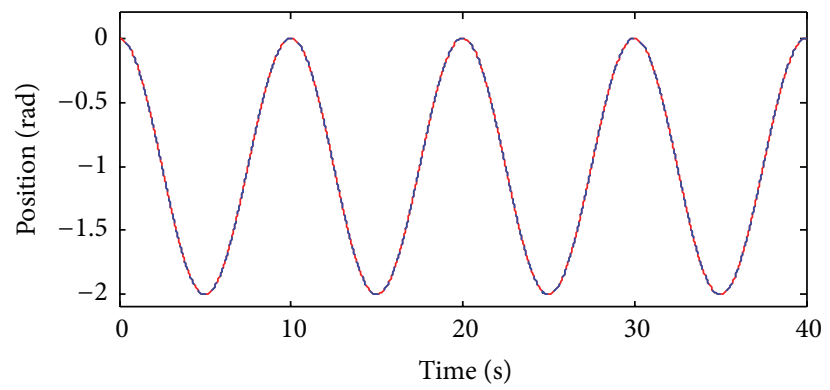

- Desired

- - - Active STW-SOSM-FTC

(c) Joint 3

FIGURE 8: The desired trajectories (dashed lines) and joint angles of the robot manipulator when an actuator fault $\delta \tau_{1}$ occurs under the Active STW-SOSM-FTC. 


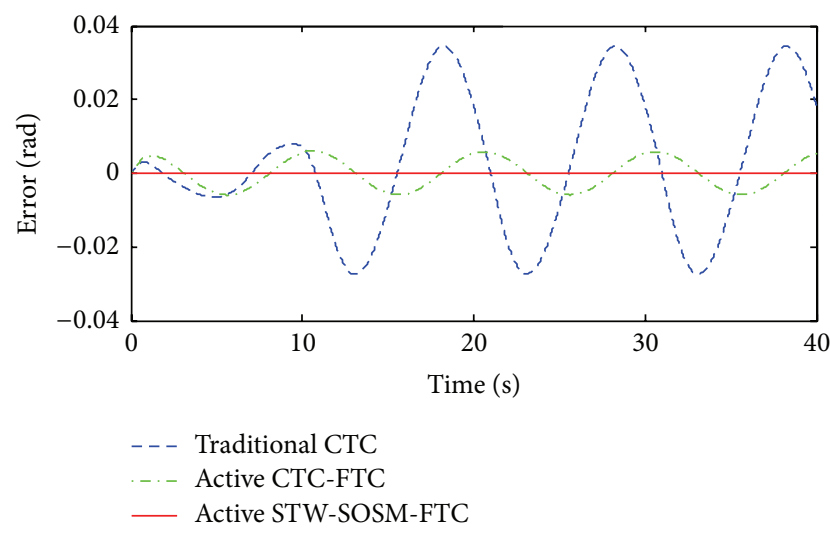

(a) Error 1

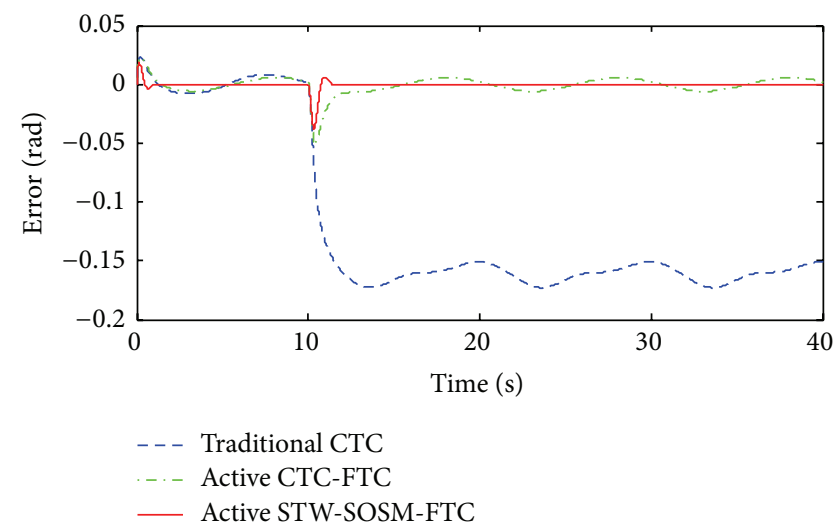

(b) Error 2

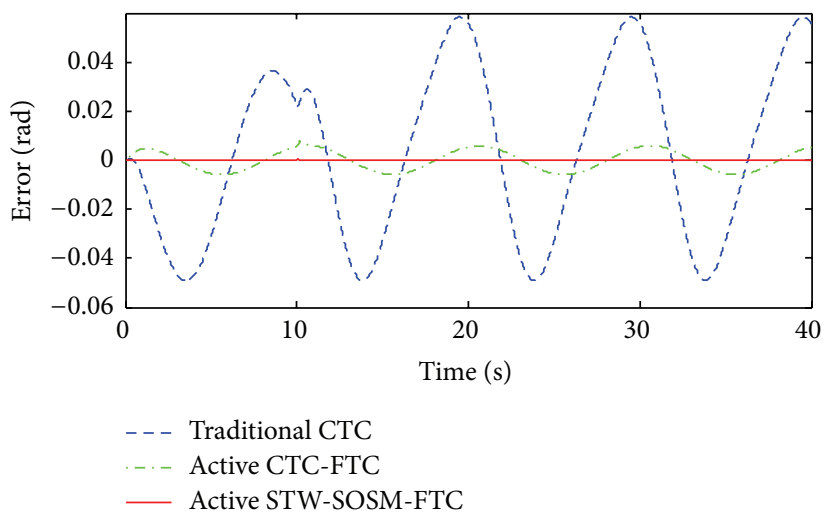

(c) Error 3

FIGURE 9: Comparison among traditional CTC, Active CTC-FTC, and Active STW-SOSM-FTC in terms of tracking error when an actuator fault $\delta \tau_{1}$ occurs.

faults. In normal operation $\phi(q, \dot{q}, \tau)=0$ and $\widehat{z}_{\text {eq }}=\widehat{\Delta}(q, \dot{q}, t)$, and then from (25) the thresholds are selected as shown in Figure 4 (dashed line). A fault is detected and isolated whenever the residual exceeds its selected thresholds.

To verify the capability of the proposed fault diagnosis scheme for fault detection and isolation as well as FTC, we supply an abrupt fault $\delta \tau_{1}$ at $t=10 \mathrm{~s}$ in the second actuator with magnitude $\delta \tau_{1}=15 \mathrm{~N}$. The response of the residuals under the effect of the given fault is illustrated in Figure 5. We can see that only the second residual overshoots the corresponding selected thresholds, which indicates that the fault occurred in the second actuator. Therefore, it can be concluded that the fault is correctly detected and isolated.

In the second phase of the simulation, the performance of the proposed active FTC is shown. The goal of the control system is to follow the desired trajectory $x_{d}=\left[x_{1 d}, x_{2 d}, x_{3 d}\right]$ with $x_{1 d}=\cos (t / 5 \pi)-1, x_{2 d}=\cos (t / 5 \pi+\pi / 2)$, and $x_{3 d}=\sin (t / 5 \pi+\pi / 2)-1$ as shown in Figure 6 (dashed line). In order to exhibit the superior performance of the proposed active FTC based on STW-SOSM (Active STWSOSM-FTC), we compared it with the traditional CTC (without the uncertainty and fault compensation) and the active FTC based on a modification of the CTC (Active CTCFTC) [3-6]. We then compared it with the passive FTC based on conventional SMC (Passive SM-FTC) and STW-SOSM control (Passive STW-SOSM-FTC) to show the capability of the active FTC compared with the passive FTC and the capability of the STW-SOSM controller compared with that of the conventional SMC.

Based on [15-18], the traditional CTC is designed as

$$
\begin{aligned}
\tau_{0} & =M\left(x_{1}\right)\left(\ddot{x}_{d}+K_{P}\left(x_{d}-x_{1}\right)+K_{V}\left(\dot{x}_{d}-\widehat{x}_{2}\right)\right. \\
& \left.+H\left(x_{1}, \hat{x}_{2}\right)\right),
\end{aligned}
$$

where $x_{d}$ is the desired trajectory and $\widehat{x}_{2}$ is the velocity estimation obtained by the STW-TOSM observer. When a fault occurs, a modified CTC is designed based on the feedback linearization technique to compensate for the effect of the fault. The CTC is designed as

$$
\tau=\tau_{0}+\tau_{c}
$$

with the fault compensation term

$$
\tau_{c}=-M\left(x_{1}\right) \widehat{z}_{\mathrm{eq}} \cdot
$$

The parameters were chosen as $K_{p}=\operatorname{diag}(15,15,15)$ and $K_{V}=\operatorname{diag}(10,10,10)$. For the proposed Active STW-FTC system, the parameters were chosen to be $k_{1}=2$ and $k_{2}=2.5$. Assuming that the upper bound of the uncertainty and fault 


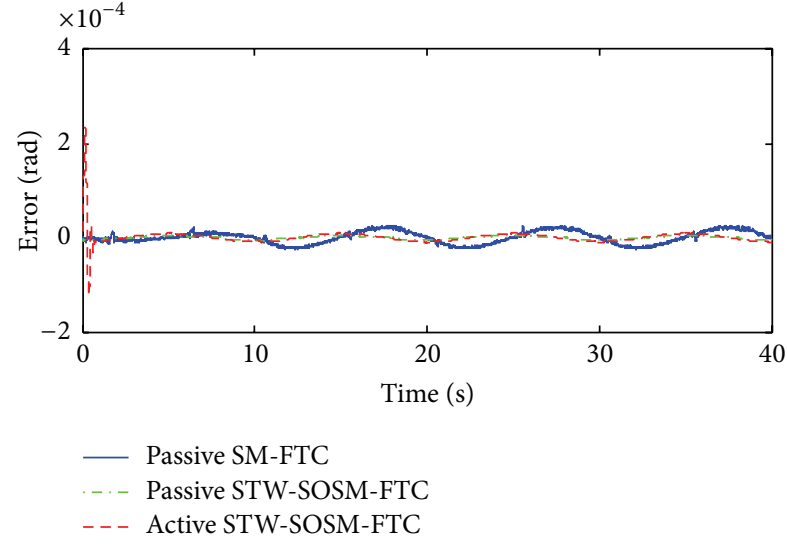

(a) Error 1

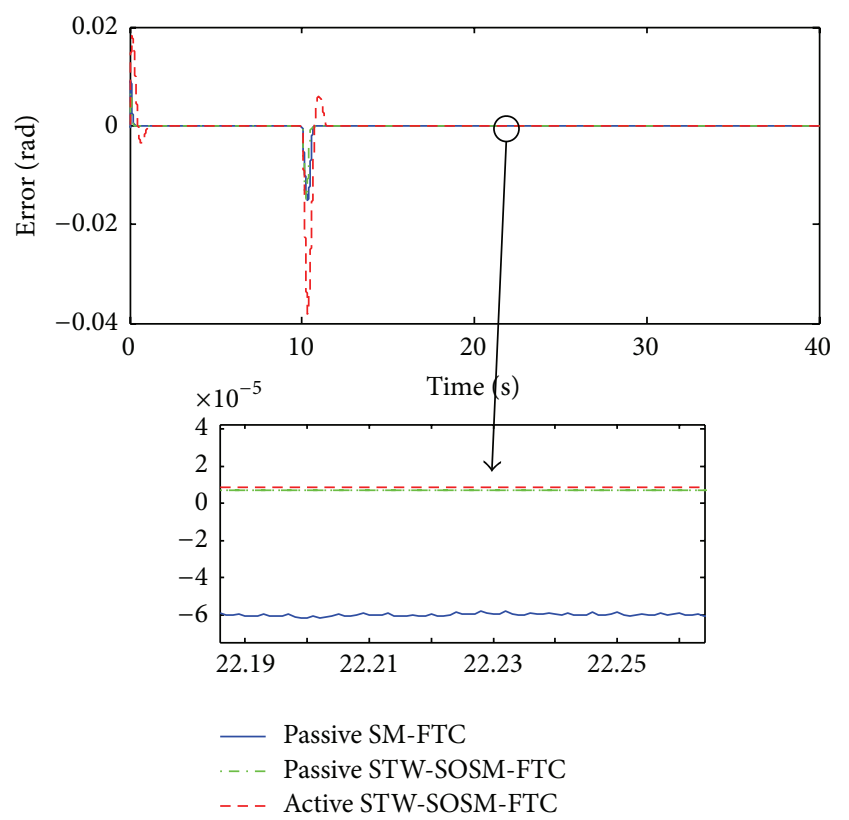

(b) Error 2

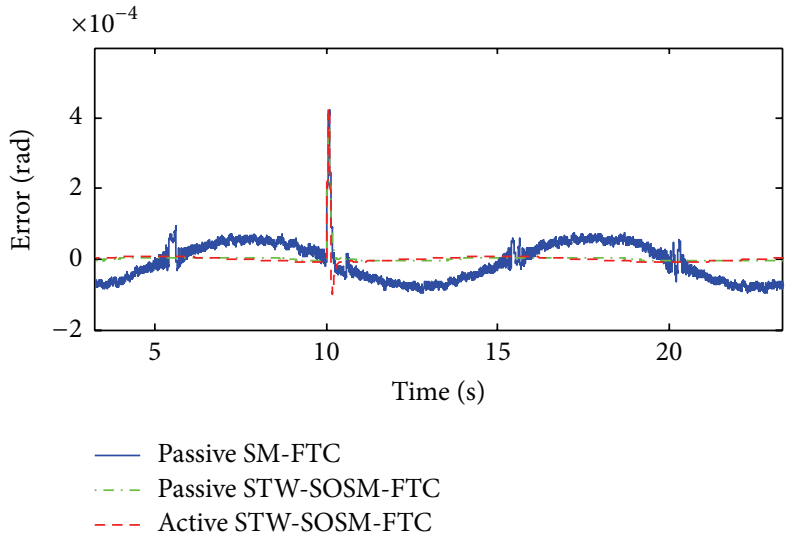

(c) Error 3

FIgURE 10: Comparison among Passive SM-FTC, Passive STW-SOSM-FTC, and Active STW-SOSM-FTC in terms of tracking error when an actuator fault $\delta \tau_{1}$ occurs.

is $\bar{C}=\bar{\Delta}+\bar{\phi}=16$, the sliding mode gain of Passive SM-FTC is selected as $\rho_{u f}=18$, and the parameters of STW for Passive STW-FTC are selected as $c_{1}=18$ and $c_{2}=60$.

When the robot is in normal operation at $t<10 \mathrm{~s}$, the tracking performance of the conventional CTC controller is shown in Figure 6. Since the CTC controller does not have the ability to accommodate the actuator faults, when a fault occurs at $t \geq 10 \mathrm{~s}$, the trajectory tracking error becomes larger. The fault estimation generated by the EOI of the STWTOSM observer is used for the design in FTC. The tracking performance of the Active CTC-FTC designed as in (34) is shown in Figure 7. Comparing Figure 7 with Figure 6 shows that the tracking performance is improved. Although the fault diagnosis observer scheme based on the STWTOSM observer can obtain the fault estimation with a slight error, the Active CTC-FTC system needs time to obtain the fault estimation and time to reconfigure the controller that provides an error. This error can be compensated by the switching SMC in the Active STW-SOSM-FTC, and the result is shown in Figure 8. A comparison of Figure 8 with Figures 6 and 7 (and the detailed comparison tracking error graph in Figure 9) shows that the proposed Active STW-SOSM-FTC has less transient response and error than the nominal CTC and Active CTC-FTC in both fault-free and fault conditions.

The simulation comparison of the Active STW-SOSMFTC with the Passive SM-FTC and Passive STW-SOSMFTC in terms of the tracking error and the control effort is shown in Figures 10 and 11. From Figure 10, the chattering and error of the Passive STW-SOSM-FTC are much smaller compared with those of conventional Passive SM-FTC. This means that the STW-SOSM controller provides less chattering and obtains higher accuracy than the conventional SMC controller. On the other hand, the response time of the Passive STW-SOSM-FTC is faster and the tracking error is slightly 

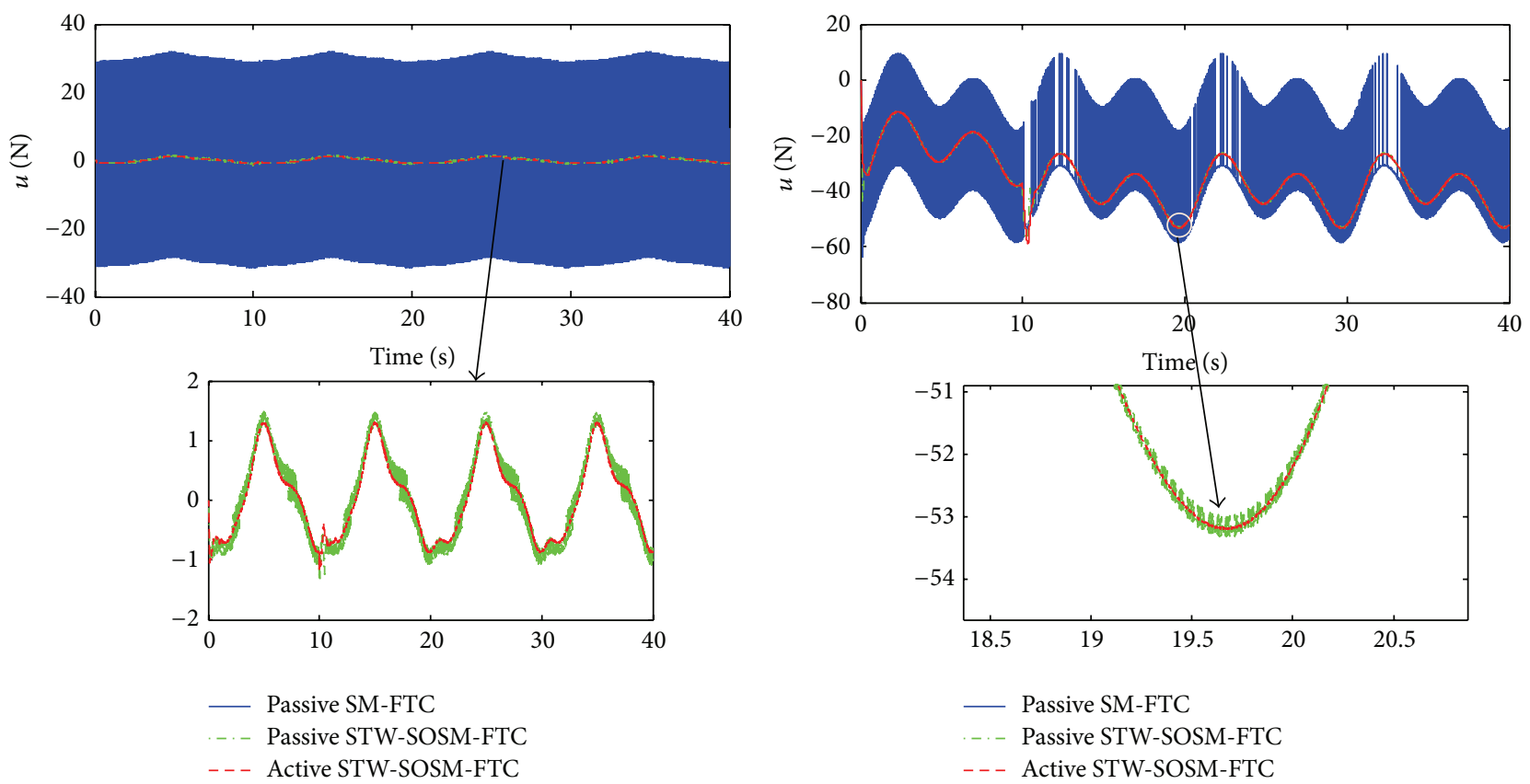

(a) Control input 1 for Joint 1

(b) Control input 2 for Joint 2

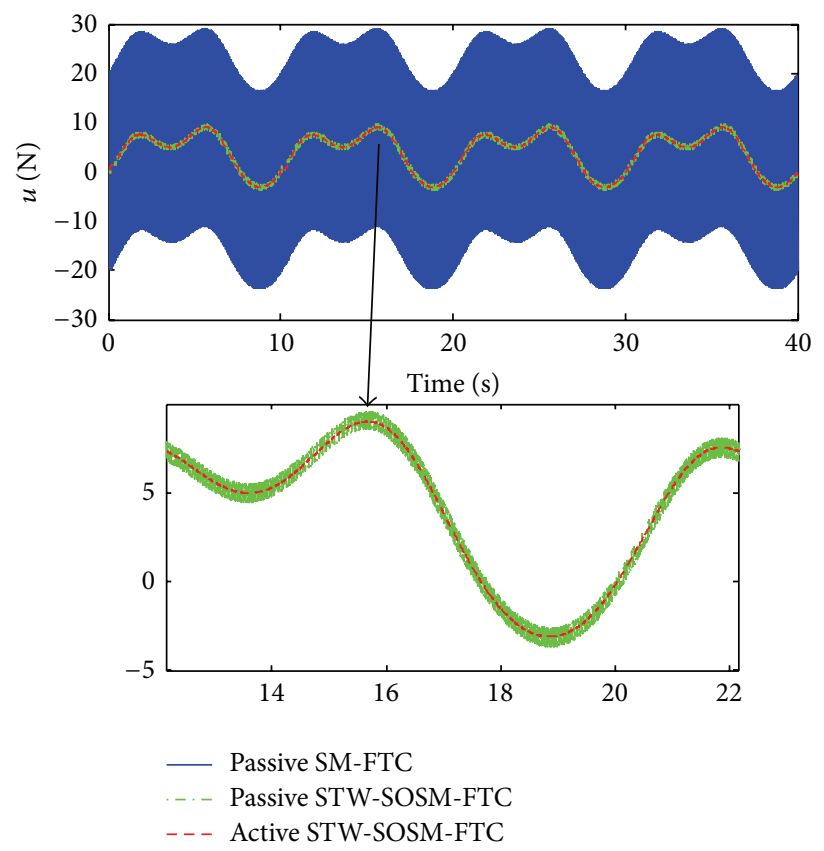

(c) Control input 3 for Joint 3

Figure 11: Comparison among Passive SM-FTC, Passive STW-SOSM-FTC, and Active STW-SOSM-FTC in terms of control effort when an actuator fault $\delta \tau_{1}$ occurs.

smaller than that of the Active STW-SOSM-FTC. However, the control efforts and the chattering of the Active STWSOSM-FTC are much smaller than those of the Passive SMFTC and Passive STW-SOSM-FTC, as shown in Figure 11.

Based on the results of the proposed Passive STW-SOSMFTC and Active STW-SOSM-FTC, some discussions can be explored for the FTC system as follows. (1) In general, the passive FTC has a faster response time than the active FTC because the passive FTC does not need time to obtain the fault information. (2) With the correct fault information, the performance of the active FTC is better than that of the passive FTC. This is because the passive FTC has to deal with the worst-case fault situation in the design process.

\section{Conclusion}

A twofold approach was successfully proposed in this paper. In the first part, a fault diagnosis scheme based on the 
STW-TOSM observer was designed. The equivalent output injection of the STW-TOSM observer, which exactly obtains the unknown input without filtration, was used as the residual for fault detection and isolation. A fault is detected and isolated whenever the residual exceeds its corresponding threshold. In the second part, an active FTC scheme based on a combination of the STW-TOSM observer and the STWSOSM controller was designed. The proposed FTC scheme could accommodate not only the fault, but also the uncertainties, and it did not require a velocity measurement. The analysis and simulation results for a PUMA560 industrial robot verify that the proposed Active STW-SOSM-FTC has great fault tolerance capability and great robustness to external disturbances and system uncertainty.

\section{Competing Interests}

The authors declare that they have no competing interests.

\section{Acknowledgments}

This study was partially supported by the UK EPSRC project EP/K019368/1: Self-Resilient Reconfigurable Assembly Systems with In-Process Quality Improvement.

\section{References}

[1] D. Ceglarek, M. Colledani, J. Váncza et al., "Rapid deployment of remote laser welding processes in automotive assembly systems," CIRP Annals_Manufacturing Technology, vol. 64, no. 1, pp. 389-394, 2015.

[2] D. Ceglarek, W. Huang, S. Zhou, Y. Ding, R. Kumar, and Y. Zhou, "Time-based competition in multistage manufacturing: stream-of-variation analysis (SOVA) methodology-Review," International Journal of Flexible Manufacturing Systems, vol. 16, no. 1, pp. 11-111, 2004.

[3] T. Tolio, D. Ceglarek, H. A. Elmaraghy et al., "SPECIES-Coevolution of products, processes and production systems," CIRP Annals - Manufacturing Technology, vol. 59, no. 2, pp. 672-693, 2010.

[4] D. Ceglarek, H. F. Li, and Y. Tang, "Modeling and optimization of end effector layout for handling compliant sheet metal parts," Journal of Manufacturing Science and Engineering, vol. 123, no. 3, pp. 473-480, 2001.

[5] D. Ceglarek and J. Shi, "Fixture failure diagnosis for autobody assembly using pattern recognition," Journal of Engineering for Industry-Transactions of the ASME, vol. 118, no. 1, pp. 55-66, 1996.

[6] D. Ceglarek and J. Shi, "Fixture failure diagnosis for sheet metal assembly with consideration of measurement noise," Transactions of the ASME, Journal of Manufacturing Science and Engineering, vol. 121, no. 4, pp. 771-777, 1999.

[7] Y. Ding, D. Ceglarek, and J. Shi, "Fault diagnosis of multistage manufacturing processes by using state space approach," Journal of Manufacturing Science and Engineering, vol. 124, no. 2, pp. 313-322, 2002.

[8] Y. Ding, J. Shi, and D. Ceglarek, "Diagnosability analysis of multi-station manufacturing processes," Journal of Dynamic Systems, Measurement and Control, vol. 124, no. 1, pp. 1-13, 2002.

[9] Z. Kong, D. Ceglarek, and W. Huang, "Multiple fault diagnosis method in multistation assembly processes using orthogonal diagonalization analysis," Journal of Manufacturing Science and Engineering, vol. 130, no. 1, Article ID 011014, 10 pages, 2008.

[10] D. Ceglarek and P. K. S. Prakash, "Enhanced piecewise least squares approach for diagnosis of ill-conditioned multistation assembly with compliant parts," Proceedings of the Institution of Mechanical Engineers, Part B: Journal of Engineering Manufacture, vol. 226, no. 3, pp. 485-502, 2012.

[11] H. Wang and D. Ceglarek, "Quality-driven sequence planning and line configuration selection for compliant structure assemblies," CIRP Annals-Manufacturing Technology, vol. 54, no. 1, pp. 31-35, 2005.

[12] Y. Ding, P. Kim, D. Ceglarek, and J. Jin, "Optimal sensor distribution for variation diagnosis in multistation assembly processes," IEEE Transactions on Robotics and Automation, vol. 19, no. 4, pp. 543-556, 2003.

[13] J. J. Gertler, "Survey of model-based failure detection and isolation in complex plants," IEEE Control Systems Magazine, vol. 8, no. 6, pp. 3-11, 1988.

[14] B. Freyermuth, "An approach to model based fault diagnosis of industrial robots," in Proceedings of the IEEE International Conference on Robotics and Automation, pp. 1350-1356, Sacramento, Calif, USA, April 1991.

[15] A. T. Vemuri and M. M. Polycarpou, "Neural-network-based robust fault diagnosis in robotic systems," IEEE Transactions on Neural Networks, vol. 8, no. 6, pp. 1410-1420, 1997.

[16] A. T. Vemuri, M. M. Polycarpou, and S. A. Diakourtis, "Neural network based fault detection in robotic manipulators," IEEE Transactions on Robotics and Automation, vol. 14, no. 2, pp. 342348, 1998.

[17] Q. Song and L. Yin, "Robust adaptive fault accommodation for a robot system using a radial basis function neural network," International Journal of Systems Science, vol. 32, no. 2, pp. 195204, 2001.

[18] Q. Song, W. J. Hu, L. Yin, and Y. C. Soh, "Robust adaptive dead zone technology for fault-tolerant control of robot manipulators using neural networks," Journal of Intelligent and Robotic Systems: Theory and Applications, vol. 33, no. 2, pp. 113-137, 2002.

[19] V. I. Utkin, Sliding Modes in Control and Optimization, Springer, Berlin, Germany, 1992.

[20] Y. Xiong and M. Saif, "Sliding mode observer for nonlinear uncertain systems," IEEE Transactions on Automatic Control, vol. 46, no. 12, pp. 2012-2017, 2001.

[21] C. Edwards, S. K. Spurgeon, and R. J. Patton, "Sliding mode observers for fault detection and isolation," Automatica, vol. 36, no. 4, pp. 541-553, 2000.

[22] M. Saif and Y. Xiong, "Sliding mode observers and their application in fault diagnosis," in Fault Diagnosis and Fault Tolerance for Mechatronic Systems: Recent Advances, vol. 1 of Springer Tracts in Advanced Robotics (STAR), pp. 1-57, Springer, 2003.

[23] X.-G. Yan and C. Edwards, "Adaptive sliding-mode-observerbased fault reconstruction for nonlinear systems with parametric uncertainties," IEEE Transactions on Industrial Electronics, vol. 55, no. 11, pp. 4029-4036, 2008.

[24] G. Bartolini, A. Ferrara, and E. Usai, "Chattering avoidance by second-order sliding mode control," IEEE Transactions on Automatic Control, vol. 43, no. 2, pp. 241-246, 1998.

[25] A. Ferrara and M. Rubagotti, "A sub-optimal second order sliding mode controller for systems with saturating actuators," IEEE Transactions on Automatic Control, vol. 54, no. 5, pp. 10821087, 2009. 
[26] G. Bartolini, A. Pisano, E. Punta, and E. Usai, "A survey of applications of second-order sliding mode control to mechanical systems," International Journal of Control, vol. 76, no. 9-10, pp. 875-892, 2003.

[27] A. Levant, "Sliding order and sliding accuracy in sliding mode control," International Journal of Control, vol. 58, no. 6, pp. 12471263, 1993.

[28] M. Van, H.-J. Kang, and K.-S. Shin, "Backstepping quasicontinuous high-order sliding mode control for a TakagiSugeno fuzzy system with an application for a two-link robot control," Proceedings of the Institution of Mechanical Engineers, Part C: Journal of Mechanical Engineering Science, vol. 228, no. 9, pp. 1488-1500, 2014.

[29] V. Mien, H.-J. Kang, and K.-S. Shin, "Adaptive fuzzy quasicontinuous high-order sliding mode controller for output feedback tracking control of robot manipulators," Proceedings of the Institution of Mechanical Engineers, Part C: Journal of Mechanical Engineering Science, vol. 228, no. 1, pp. 90-107, 2014.

[30] J. Davila, L. Fridman, and A. Levant, "Second-order slidingmode observer for mechanical systems," IEEE Transactions on Automatic Control, vol. 50, no. 11, pp. 1785-1789, 2005.

[31] J. Davila, L. Fridman, and A. Poznyak, "Observation and identification of mechanical systems via second order sliding modes," International Journal of Control, vol. 79, no. 10, pp. 1251-1262, 2006.

[32] M. Van, H.-J. Kang, and Y.-S. Suh, "Second order sliding modebased output feedback tracking control for uncertain robot manipulators," International Journal of Advanced Robotic System, vol. 10, article 16, 9 pages, 2013.

[33] M. Van, H.-J. Kang, Y.-S. Suh, and K.-S. Shin, "A robust fault diagnosis and accommodation scheme for robot manipulators," International Journal of Control, Automation and Systems, vol. 11, no. 2, pp. 377-388, 2013.

[34] M. Van, H.-J. Kang, and Y.-S. Suh, "A novel neural secondorder sliding mode observer for robust fault diagnosis in robot manipulators," International Journal of Precision Engineering and Manufacturing, vol. 14, no. 3, pp. 397-406, 2013.

[35] Q. Wu and M. Saif, "Robust fault diagnosis of a satellite system using a learning strategy and second order sliding mode observer," IEEE Systems Journal, vol. 4, no. 1, pp. 112-121, 2010.

[36] M. Van, H.-J. Kang, and Y.-S. Suh, "A novel fuzzy second-order sliding mode observer-controller for a T-S fuzzy system with an application for robot control," International Journal of Precision Engineering and Manufacturing, vol. 14, no. 10, pp. 1703-1711, 2013.

[37] L. M. Capisani, A. Ferrara, A. Ferreira De Loza, and L. M. Fridman, "Manipulator fault diagnosis via higher order slidingmode observers," IEEE Transactions on Industrial Electronics, vol. 59, no. 10, pp. 3979-3986, 2012.

[38] L. Fridman, A. Levant, and J. Davila, "Observation of linear systems with unknown inputs via high-order sliding-modes," International Journal of Systems Science, vol. 38, no. 10, pp. 773791, 2007.

[39] L. Fraguela, L. Fridman, and V. V. Alexandrov, "Position stabilization of a Stewart platform: high-order sliding mode observers based approach," Journal of the Franklin Institute, vol. 349, no. 2, pp. 441-455, 2012.

[40] M. Van, H.-J. Kang, Y.-S. Suh, and K.-S. Shin, "Output feedback tracking control of uncertain robot manipulators via higherorder sliding-mode observer and fuzzy compensator," Journal of Mechanical Science and Technology, vol. 27, no. 8, pp. 24872496, 2013.
[41] Z. Gao, C. Cecati, and S. X. Ding, "A survey of fault diagnosis and fault-tolerant techniques-part I: fault diagnosis with model-based and signal-based approaches," IEEE Transactions on Industrial Electronics, vol. 62, no. 6, pp. 3757-3767, 2015.

[42] J. Jiang and X. Yu, "Fault-tolerant control systems: a comparative study between active and passive approaches," Annual Reviews in Control, vol. 36, no. 1, pp. 60-72, 2012.

[43] M. Van, S. S. Ge, and H. Ren, "Robust fault tolerant control for a class second-order nonlinear systems using an adaptive thirdorder sliding mode control," IEEE Transactions on Systems, Man, and Cybernetics: Systems, 2016.

[44] M. Benosman and K.-Y. Lum, "Passive actuators' fault-tolerant control for affine nonlinear systems," IEEE Transactions on Control Systems Technology, vol. 18, no. 1, pp. 152-163, 2010.

[45] R. Wang and J. Wang, "Passive actuator fault-tolerant control for a class of overactuated nonlinear systems and applications to electric vehicles," IEEE Transactions on Vehicular Technology, vol. 62, no. 3, pp. 972-985, 2013.

[46] X. Zhang, T. Parisini, and M. M. Polycarpou, "Adaptive faulttolerant control of nonlinear uncertain systems: an information-based diagnostic approach," IEEE Transactions on Automatic Control, vol. 49, no. 8, pp. 1259-1274, 2004.

[47] M. Van, S. S. Ge, and H. Ren, "Finite time fault tolerant control for robot manipulators using time delay estimation and continuous nonsingular fast terminal sliding mode control," IEEE Transactions on Cybernetics, 2016.

[48] M. Van and H.-J. Kang, "Robust fault-tolerant control for uncertain robot manipulators based on adaptive quasi-continuous high-order sliding mode and neural network," Proceedings of the Institution of Mechanical Engineers, Part C: Journal of Mechanical Engineering Science, vol. 229, no. 8, pp. 1425-1446, 2015.

[49] L. M. Capisani, A. Ferrara, and L. Magnani, "Design and experimental validation of a second-order sliding-mode motion controller for robot manipulators," International Journal of Control, vol. 82, no. 2, pp. 365-377, 2009.

[50] J. A. Moreno and M. Osorio, "A Lyapunov approach to secondorder sliding mode controllers and observers," in Proceedings of the 47th IEEE Conference on Decision and Control (CDC '08), pp. 2856-2861, Cancun, Mexico, December 2008.

[51] B. Armstrong, O. Khatib, and J. Burdick, "The explicit dynamic model and inertial parameters of the PUMA 560 arm," in Proceedings of the IEEE International Conference on Robotics and Automation, vol. 3, pp. 510-518, 1986.

[52] M. Van, D. Wu, S. S. Ge, and H. Ren, "Fault diagnosis in imagebased visual servoing with eye-in-hand configuration using Kalman filter," IEEE Transactions on Industrial Informatics, 2016. 


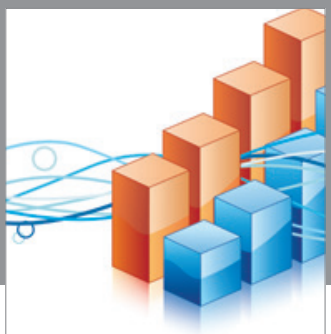

Advances in

Operations Research

vatem alat4

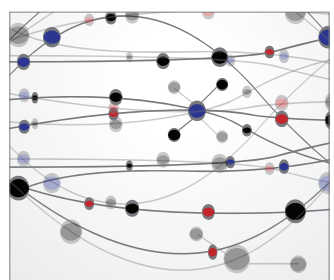

\section{The Scientific} World Journal
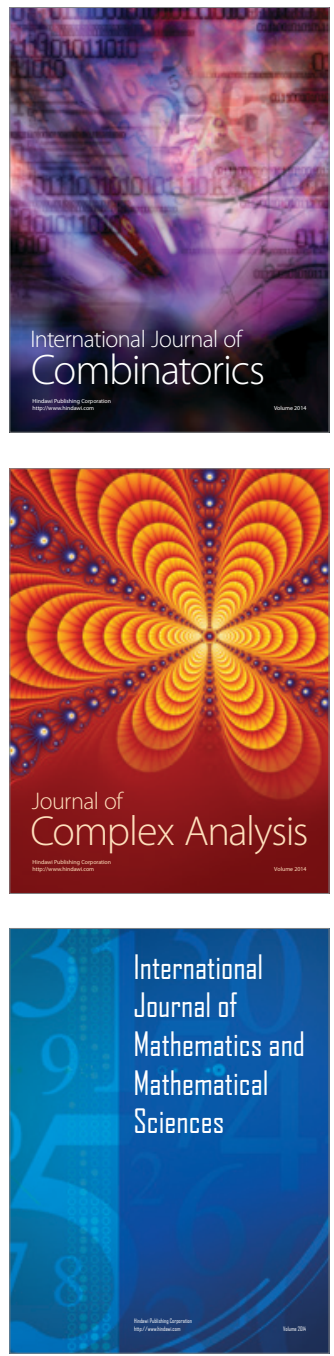
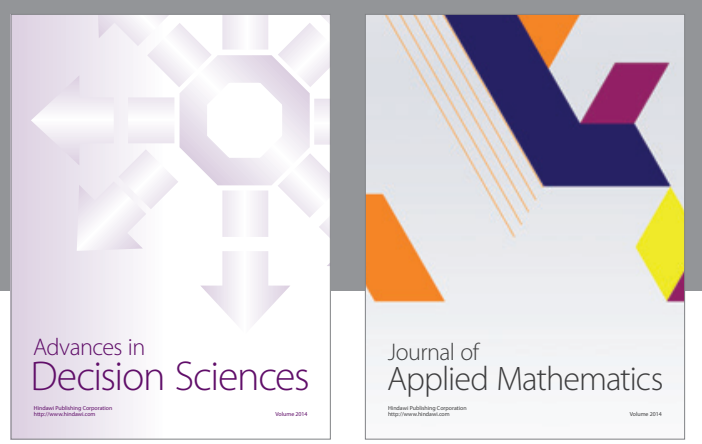

Algebra

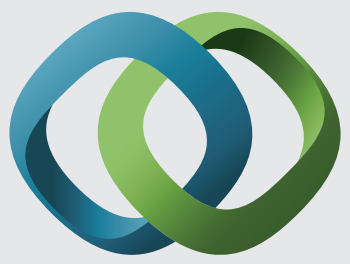

\section{Hindawi}

Submit your manuscripts at

http://www.hindawi.com
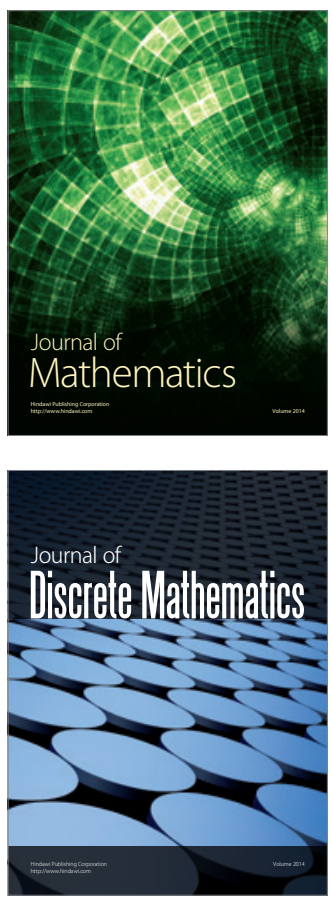

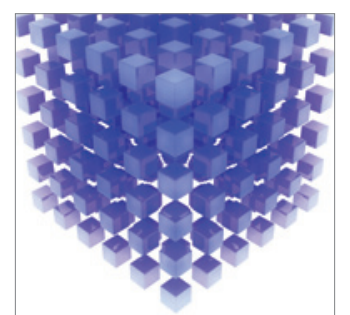

Mathematical Problems in Engineering
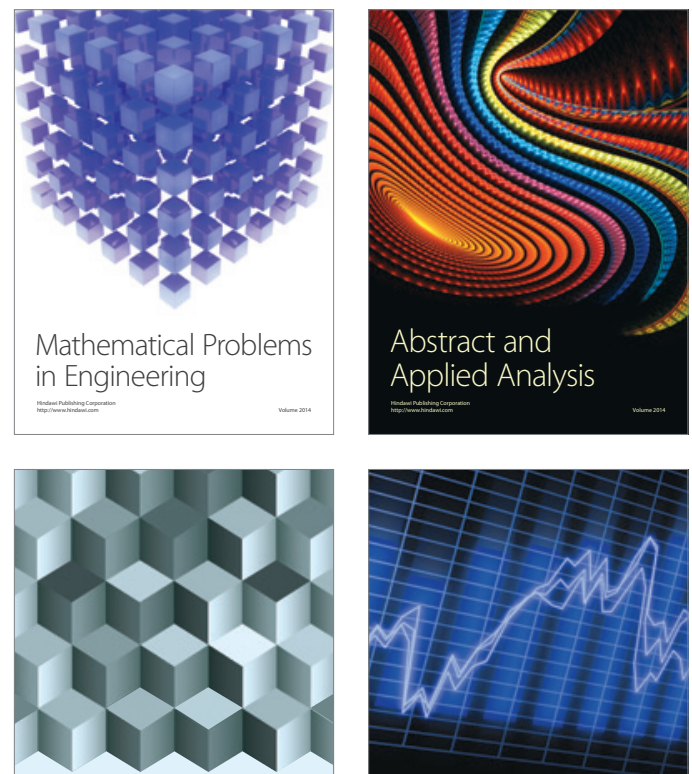

Journal of

Function Spaces

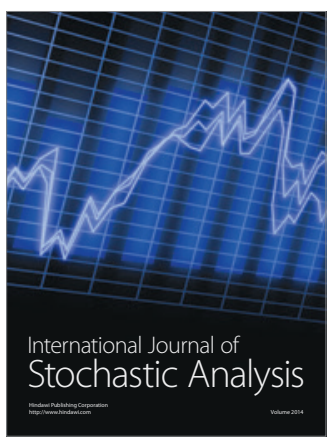

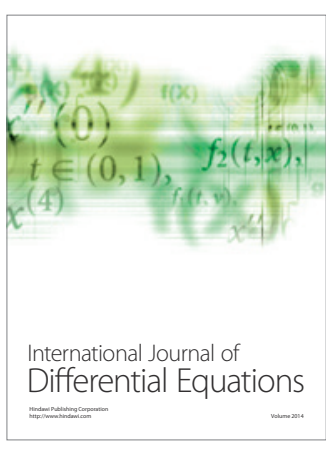
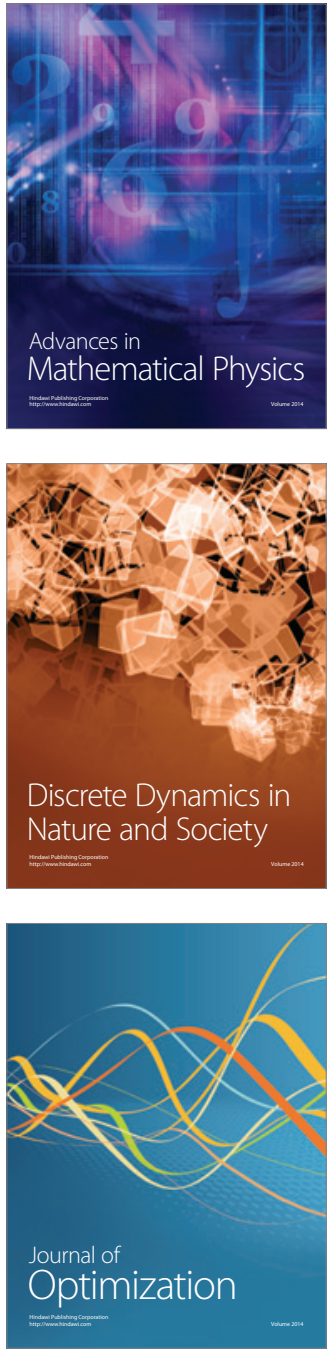